\title{
Comment on 'Effect of population breast screening on breast cancer mortality up to 2005 in England and Wales: an individual-level cohort study'
}

\author{
Anthony B Miller ${ }^{*}, 1$
}

${ }^{1}$ Professor Emeritus, Dalla Lana School of Public Health, University of Toronto, Port Hope, Ontario L1A 1T3, Canada

Sir,

Johns et al (2017) reported 'a substantial, statistically significant reduction in breast cancer mortality between 1991 and 2005 associated with NHSBSP (UK NHS breast screening programme) activity'.

The term 'associated' is appropriate as there was uncontrolled confounding with treatment and better breast cancer management. The UK breast screening programme could not be introduced everywhere at once because the facilities were not available everywhere. The initial areas included had to have been selected because they already had the necessary diagnostic and treatment facilities and expertise, hence better treatment. And since, as better treatment is the dominant cause of the fall in breast cancer mortality seen since 1990 in many countries, including the UK (Jatoi and Miller, 2003), that must have been largely responsible for the differences seen by Johns et al (2017).

As we demonstrated in Canada (Miller et al, 1992a, b, 2000, 2002, 2014), it is not possible to demonstrate a reduction in breast cancer mortality due to mammography screening in an era of modern adjuvant therapy for breast cancer. Those observational studies that attempt to do so cannot escape bias and confounding - even those studies that perform complicated approaches to adjustment for selection bias (e.g., that of Morrell et al, 2017). This fact, together with the acknowledged complications from mammography screening, especially from overdiagnosis (Baines et al, 2016), should lead us to re-consider screening with mammography, and instead concentrate on the simpler approach the World Health Organization (WHO) defines as early diagnosis of breast cancer (WHO, 2017), namely 'the early identification of cancer in patients who have symptoms of the disease'.

WHO (2017) distinguishes between screening and early diagnosis of cancer, both resulting in early detection of cancer. Early diagnosis is probably best understood as what is now called 'breast awareness': encouraging women by public education to be aware of the appearance and feel of their breasts, and if she detects an abnormality in her breast to seek skilled examination by physicians who know the signs of early breast cancer, followed by appropriate diagnostic tests - diagnostic mammography and/or ultrasound.

\section{CONFLICT OF INTEREST}

The author declares no conflict of interest.

\section{REFERENCES}

Baines CJ, To T, Miller AB (2016) Revised estimates of overdiagnosis from the Canadian National Breast Screening Study. Prev Med 90: 66-71.

Jatoi I, Miller AB (2003) Why is breast cancer mortality declining? Lancet Oncol 4: $251-254$

Johns LE, Coleman DA, Swerdlow AJ, Moss SM (2017) Effect of population breast screening on breast cancer mortality up to 2005 in England and Wales: an individual-level cohort study. $\mathrm{Br} J$ Cancer 116: 246-252.

Miller AB, Baines CJ, To T, Wall C (1992a) Canadian national breast screening study: 1. Breast cancer detection and death rates among women age 40-49 years. CMAJ 147: 1459-1476.

Miller AB, Baines CJ, To T, Wall C (1992b) Canadian national breast screening study: 2. Breast cancer detection and death rates among women age 50-59 years. CMAJ 147: 1477-1488.

Miller AB, To T, Baines CJ, Wall C (2000) Canadian National Breast Screening Study-2: 13-year results of a randomized trial in women age 50-59 years. J Natl Cancer Inst 92: 1490-1499.

Miller AB, To T, Baines CJ, Wall C (2002) The Canadian National Breast Screening Study-1: Breast cancer mortality after 11 to 16 years of follow-up. A randomized screening trial of mammography in women age 40 to 49 years. Ann Intern Med 137: 305-312.

Miller AB, Wall C, Baines CJ, Sun P, To T, Narod SA (2014) Twenty five year follow-up for breast cancer incidence and mortality of the Canadian National Breast Screening Study: randomised screening trial. $B M J$ 348: g366.

Morrell S, Taylor R, Roder D, Robson B, Gregory M, Craig K (2017) Mammography service screening and breast cancer mortality in New Zealand: a National Cohort Study 1999-2011. Br J Cancer 116: 828-839.

WHO (2017) Guide to Cancer Early Diagnosis. World Health Organization: Geneva.

This work is published under the BJC's standard license to publish agreement. After 12 months the license terms will change to a Creative Commons AttributionNonCommercial-Share Alike 4.0 Unported License.

*Correspondence: Dr AB Miller; E-mail: ab.miller@sympatico.ca

Published online 11 April 2017

(C) 2017 Cancer Research UK. All rights reserved 0007-0920/17 